\title{
Filling the gap between $h n s$ and adhE in Escherichia coli K12
}

\author{
Antoine Danchin and Evelyne Krin
}

Author for correspondence: Antoine Danchin. Tel: +331 456884 41. Fax: +331 45688948. e-mail: adanchin@pasteur.fr

Régulation de l'Expression Génétique, Institut

Pasteur, 28 rue du Docteur Roux 75724 Paris Cedex 15, France

\begin{abstract}
As a consequence of the absence of a general coordination process in the sequencing of the Escherichia coli K12 genome, to completely sequence the genome in a reasonable time it is important to fill in gaps between known regions. We report the sequence of the $h n s-a d h$ region, at $27 \mathrm{~min}$ on the genome.
\end{abstract}

Keywords: Escherichia coli $\mathrm{K} 12$, bns, tdk, IS4, genome sequencing
The region including the bns gene is somewhat unusual in Escherichia coli because this gene has been identified as being involved in many different cellular functions, e.g. virulence, control of osmolarity, control of pili or curli synthesis (see references quoted by Lucht et al., 1994, and Tupper et al., 1994). Moreover the hns gene itself has been sequenced several times, and mapped at different positions on the genome. In particular the work by Gualerzi and coworkers gave a mistaken location of the gene because the sequenced fragment was presumably chimaeric (Pon $\mathrm{et}$ al., 1988). It is therefore interesting to place the gene in context. Here we report the 3060-nucleotide sequence encompassing most of the hns gene as well as the upstream region bordering the adb gene.

The sequence was obtained by subcloning into pBR322 a fragment complementing an bns defect, and then screening for thymidine kinase activity. The restriction map of the cloned fragment is identical to the known restriction map of the region (see Fig. 1). The fragment was then sequenced on both strands using the method of Sanger et al. (1977). Table 1 lists the characteristics of the $h n s-a d b E$ region.

The sequenced region also includes the $t d k$ gene, encoding thymidylate kinase, and an unknown coding sequence (CDS) which encodes a putative protein displaying significant similarity to an hypothetical 442-residue protein encoded by the E. coli insertion element IS4 (see Fig. 2).

In addition, a small segment of the $657 \mathrm{bp}$ region of the $E$. coli genome upstream of an IS 5 insertion, in which Liu \& Reeves (1994) proposed that a rearrangement had oc-

Abbreviations: CDS, coding sequence; RBS, ribosome-binding site. The EMBL accession number for the nucleotide sequence reported in this paper is $X 67326$.

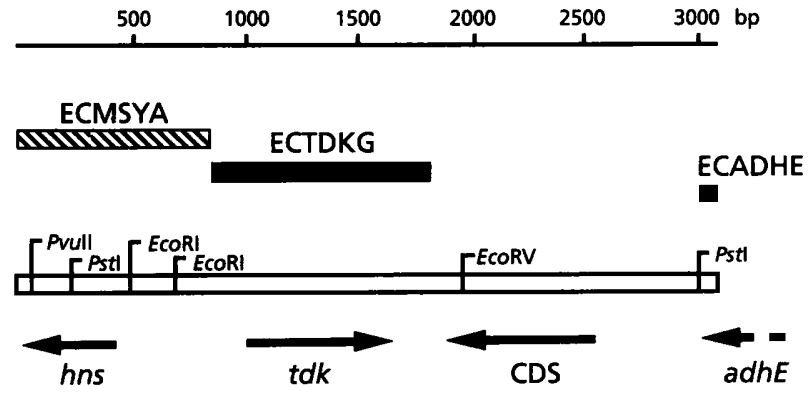

Fig. 1. Restriction map of the hns-adhE region. Known sequences, present in the EMBL database [accession numbers X59940 (ECMSYA), X53733 (ECTDKG), and M33504 (ECADHE)], are aligned with respect to the base positions of the sequenced fragment. Restriction sites of the Kohara map are also shown, and the gene coding sequences, arrowed, are displayed underneath the restriction map.

Table 1. The hns-adhE region

\begin{tabular}{|lrll|}
\hline Feature & Position & Identification & Orientation \\
\hline bns CDS & $1-405$ & Experimental & Complement \\
bns RBS & $414-417$ & Similarity & Complement \\
bns promoter -10 & $447-453$ & Similarity & Complement \\
bns promoter -35 & $471-476$ & Similarity & Complement \\
$t d k$ promoter -35 & $937-942$ & Similarity & Direct \\
$t d k$ promoter -10 & $959-964$ & Similarity & Direct \\
$t d k$ RBS & $995-998$ & Similarity & Direct \\
$t d k$ CDS & $1010-1624$ & Experimental & Direct \\
IS4 insert-like CDS & $1912-2499$ & Pattern & Complement \\
& & similarity & \\
Palindrome & $2809-2838$ & Pattern & Direct \\
Palindrome & $2850-2875$ & Pattern & Direct \\
adbE CDS & $2932-3060$ & Similarity & Complement \\
\hline
\end{tabular}




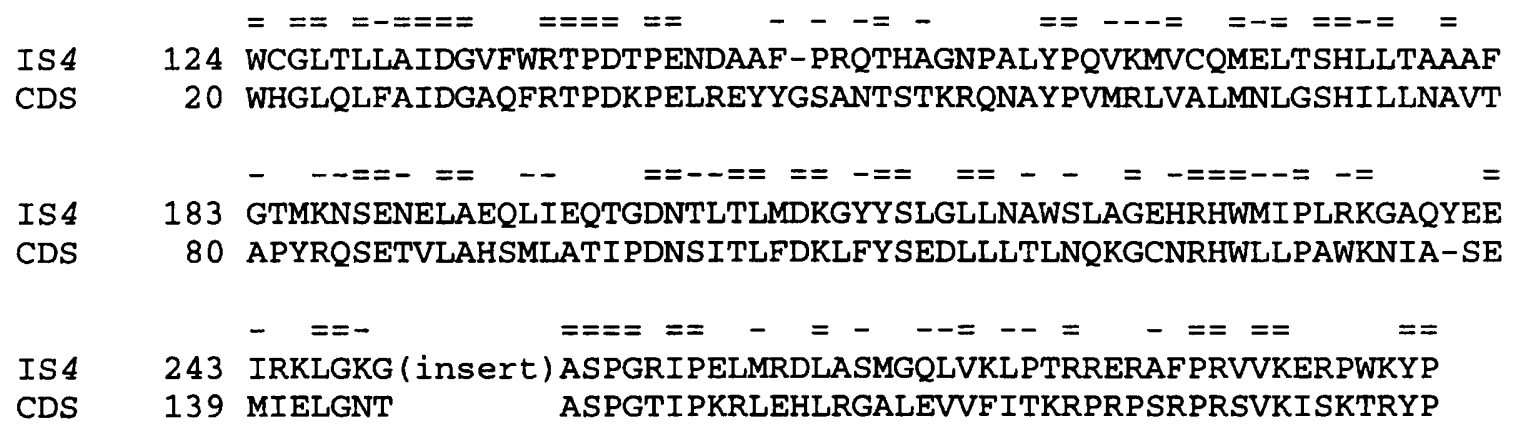

Fig. 2. Comparison of amino acid sequences of IS4-encoded protein and IS4 insert-like CDS.

curred, is almost identical to part of this IS4-encoded protein. It seems therefore that the CDS identified in the $b n s-a d b E$ region, which is similar to an IS4-encoded protein, is a scar of some insertion event, a phenomenon which is likely to be observed elsewhere on the E. coli genome.

\section{REFERENCES}

Liu, D. \& Reeves, P. R. (1994). Eschericbia coli K12 regains its $O$ antigen. Microbiology 140, 49-57.

Lucht, J. M., Dersch, P., Kempf, B. \& Bremer, E. (1994). Interactions of the nucleotide-associated DNA-binding protein H-NS with the regulatory region of the osmotically controlled proU operon of Escherichia coli. J Biol Chem 269, 6578-6588.
Pon, C. L., Calogero, R. A. \& Galerzi, C. O. (1988). Identification, cloning, nucleotide sequence and chromosomal map location of hns, the structural gene for Escherichia coli DNA-binding protein $\mathrm{H}$ NS. Mol \& Gen Genet 212, 199-202.

Sanger, F., Nicklen, S. \& Coulson, A. R. (1977). DNA sequencing with chain-terminating inhibitors. Proc Natl Acad Sci USA 74, 5463-5467.

Tupper, A. E., Owen-Hughes, T. A., Ussery, D. W., Santos, D. S., Ferguson, D. J., Sidebotham, J. M., Hinton, J. C. \& Higgins, C. F. (1994). The chromatin-associated protein H-NS alters DNA topology in vitro. EMBO J 13, 258-268.

Received 31 October 1994; revised 5 January 1995; accepted 11 January 1995. 